\title{
Capacidade de reidratação e influência do corte no restabelecimento do fluxo de água em inflorescências de Epidendrum ibaguense ${ }^{(1)}$
}

\author{
JOICE SIMONE DOS SANTOS(2); FERNANDO LUIZ FINGER(3); LUCIANA MARQUES VIEIRA(2); \\ TERESA DRUMMOND CORREIA MENDES(2); JOSÉ GERALDO BARBOSA(3)
}

\begin{abstract}
RESUMO
Este trabalho teve por objetivos avaliar o efeito do tempo de armazenamento a seco na obstrução e reidratação de flores de E. ibaguense e a influência do comprimento do corte na base da haste na recuperação da absorção de água. As inflorescências foram colhidas e padronizadas em $30 \mathrm{~cm}$, em seguida, armazenadas a seco a $24^{\circ} \mathrm{C}$ por $12,24,36$ e 48 horas. Ao final de cada período de estresse, as inflorescências retornaram para água por 24 horas e durante este período foram analisadas alterações da massa fresca, teor relativo de água (TRA) das pétalas e posterior vida de vaso em água. Em outro experimento, as inflorescências foram armazenadas a seco por 36 horas e, após, foi feito o corte da base das hastes florais com comprimento de 0,$5 ; 1,0 ; 2,0 ; 3,0$ e 4,0 cm e então colocadas em vasos com água desionizada. As hastes armazenadas por 12 horas a seco recuperaram a massa fresca e o TRA quando colocadas em água, mas não houve recuperação nas hastes com 24, 36 ou 48 horas de estresse hídrico. Independentemente da duração do armazenamento a seco, houve redução da vida de vaso quando comparado com a das inflorescências controle sem estresse hídrico. $\mathrm{O}$ corte de $0,5 \mathrm{~cm}$ em inflorescências armazenadas a seco por 36 horas não prolongou a vida de vaso, mas os cortes de 1,0;2,0;3,0 e 4,0 cm elevaram a vida de vaso em relação ao controle sem corte. Os cortes de 1,0;2,0;3,0 e 4,0 cm na base da haste aumentaram a capacidade de absorção de água, baixando temporariamente a razão transpiração/absorção de água das inflorescências.

Palavras-chave: massa fresca, teor relativo de água, transpiração, vida de vaso, Epidendrum ibaguense Kunth.
\end{abstract}

ABSTRACT

Capacity of rehydration and influence of cut on the recovery of water flow in inflorescences of Epidendrum ibaguense

This study had the goals to evaluate the effect of the dry storage length on the occlusion and rehydration of E. ibaguense inflorescences, and the influence of the cut at the basis of the stem on the recovery of water uptake. The inflorescences were harvested patronized to $30 \mathrm{~cm}$, long, followed by dry storage at $24^{\circ} \mathrm{C}$ for $12,24,36$ and 48 hours. At the end of each stress period, the inflorescences returned to the water for 24 hours, and during this period, it was determined the alterations on the fresh mass and the relative water content (RWC) of petals, followed by the length of vase life. In another experiment, the inflorescences were dry stored for 36 hours, and after it was done cut at the lower base of the stem with lengths varying from $0.5,1.0,2.0,3.0$ and $4.0 \mathrm{~cm}$, and then placed in deionized water. The inflorescences dry stored for 12 hours recovered the fresh mass and RWC when placed in water, but there was no recovery when the inflorescences had 24, 36 or 48 hours of water stress. Regardless the length of the dry storage, there was reduction of flower vase life compared to inflorescences without water stress. The $0.5 \mathrm{~cm}$ cut at the base of the stem after 36 hours of dry storage, did not affect the vase life, but cuts of 1.0, 2.0, 3.0 or $4.0 \mathrm{~cm}$ increased the vase life compared to control flowers without any cut. Cuts of 1.0, 2.0, 3.0 or $4.0 \mathrm{~cm}$ at the base of the stem enhanced the water uptake, lowering temporarily the rate transpiration: water uptake of the inflorescences.

Keywords: fresh matter, relative water content, transpiration, vase life, Epidendrum ibaguense Kunth.

\section{INTRODUÇÃO}

A orquídea Epidendrum ibaguense tem inflorescência do tipo umbela, com flores pequenas de coloração vermelha e alaranjada, com labelo amarelo e haste longa, podendo ser utilizada como flor de corte, de vaso ou ainda em paisagismo. Além disso, é de fácil cultivo e, por produzir durante o ano inteiro, apresenta grande potencial para comercialização (MENEGUCE et al., 2004). Em estudo recente, esta flor tem mostrado grande aptidão para uso como flor de corte devido à sua boa aceitação pelo mercado consumidor e hastes relativamente longas para o uso em vaso (MORAES et al., 2009).

O controle da senescência em flores de corte é um processo que varia entre espécies e requer a otimização das relações hídricas para a redução da abscisão e murchamento das pétalas e flores. Durante a comercialização, a maioria das flores de corte são transportadas e armazenadas a seco, o que pode causar a murcha permanente mesmo quando, após o transporte são postas em água. Isso ocorre porque as hastes florais permanecem com a base exposta ao ar, causando o bloqueio e secamento dos vasos condutores,

\footnotetext{
(1) Recebido em 12/10/2012 e aceito para publicação em 27/01/2012

(2) Universidade Federal de Viçosa (UFV) - Departamento de Biologia Vegetal. e-mail: joicessm@gmail.com; lcsmarques@yahoo.com.br; tdcorreia@ gmail.com.

(3)UFV, Departamento de Fitotecnia. e-mail: ffinger@ufv.br; jgeraldo@ufv.br.
} 
prejudicando a absorção de água e a posterior reidratação (VAN DOORN, 1997).

A reidratação visa a restaurar o balanço hídrico das flores de corte transportadas e armazenadas a seco pelo restabelecimento da turgidez, saturando os tecidos com água ou soluções conservantes (SUZUKI et al., 2001). Trabalhos desenvolvidos por DURKIN (1980) demonstraram que a inclusão de conservantes na água pode maximizar a reidratação das flores cortadas armazenadas a seco. No entanto, alguns solutos, como $\mathrm{NaCl}$ e sacarose, quando adicionados à água, a depender da quantia aplicada, aumentam a viscosidade da solução de vaso, o que pode reduzir a absorção.

Quando flores de corte são colocadas em condições de estresse, como armazenamento a seco, ocorre uma tensão no sistema vascular, favorecendo a entrada de ar nas extremidades das hastes florais cortadas e, assim, como consequência, ocorre cavitação nos vasos condutores, um dos principais fatores que causam o déficit de água (VAN DOORN, 1997). Na planta, as bolhas de ar alojamse nas paredes dos vasos do xilema, impedindo o fluxo de água. Após a retirada da embolia, algumas espécies são capazes de restaurar o potencial hídrico normal, caso da Strelitzia reginae Banks (CAMPANHA et al., 1997), Zinnia elegans Jack (CARNEIRO et al., 2002) Leptospermum rotundifolium Domin (FARAGHER et al., 2002), enquanto outras não, como a Alpinia purpurata Vieiil (SILVA, 2006). Em E. ibaguense, não é conhecido se há obstrução dos vasos após um período de armazenamento a seco.

A senescência e o murchamento das flores ou inflorescências de corte estão associados à redução da absorção de água pelas hastes. Para VAN MEETEREN et al. (2001), o murchamento precoce ocorre como resultado da perda prematura do turgor das células, devido ao desbalanço entre a absorção de água e a transpiração, durante certo período de tempo. A causa deste desequilíbrio é a alta taxa transpiratória ou absorção de água limitada pela alta resistência ou baixa condutância hidráulica dos vasos xilemáticos. O déficit hídrico desenvolve-se quando a taxa de absorção de água é menor que a de transpiração das flores.

Uma forma de reverter ou amenizar o estresse hídrico sofrido por muitas flores de corte é realizar o corte periódico da base da haste em água, uma vez que favorece o aumento da taxa de absorção de água e evita a cavitação dos vasos (CAMPANHA et al., 1997; BLEEKSMA e VAN DOORN, 2003). Este efeito foi observado em flores de Zinnia elegans, ocorrendo um prolongamento da vida de vaso em até dois dias pela maior hidratação (CARNEIRO et al., 2002). Por outro lado, segundo FARAGHER et al. (2002), o corte periódico nem sempre é prático e, além disso, em algumas espécies, o corte da base não manteve a qualidade e vida de vaso das flores, conforme foi observado em rosas por LEONARD et al. (2001).

Este trabalho teve por objetivos avaliar o efeito do tempo de armazenamento a seco sobre a capacidade de absorção de água, reidratação e vida de vaso das inflorescências de E. ibaguense, bem como a influência do comprimento do corte da base no restabelecimento da absorção de água pelas hastes florais.

\section{MATERIAL E MÉTODOS}

As hastes de Epidendrum ibaguense Kunth foram colhidas no campo de produção da Universidade Federal de Viçosa-UFV, sempre no período da manhã. O ponto de colheita adotado foi quando a inflorescência apresentava 15 a 20 flores abertas, conforme estabelecido por MORAES et al. (2007). Foram conduzidos dois experimentos: o primeiro para avaliar se as inflorescências de E. ibaguense eram capazes de recuperar sua turgescência após estresse hídrico, e o segundo, para constatar o efeito do corte da base no restabelecimento da absorção de água após o armazenamento a seco.

Após a colheita, as hastes foram colocadas em recipientes contendo água e, em seguida, levadas ao laboratório onde foram feitos o corte da base da haste em água e a padronização do seu comprimento para $30 \mathrm{~cm}$.

Para verificar a capacidade de reidratação das inflorescências após o armazenamento a seco, as hastes florais foram armazenadas à temperatura de $24 \pm 2^{\circ} \mathrm{C}$ e UR de $85 \pm 2 \%$ por $12,24,36$ e 48 horas, permanecendo acomodadas em recipientes de plástico forrados com papel toalha até retornarem à água ao final de cada período. As inflorescências controle permaneceram sempre em recipientes contendo $200 \mathrm{~mL}$ de água desionizada, não sofrendo déficit hídrico. Durante 24 horas, foram determinados a variação de massa fresca e o teor relativo de água e vida de vaso das inflorescências, com intervalo entre as avaliações de 4 horas, a partir do início da reidratação.

Ao primeiro período analisado, ou seja, antes de serem submetidas ao armazenamento a seco, foi atribuída uma massa inicial de $100 \%$. A variação de massa fresca foi estimada como percentual em relação à massa inicial das hastes como descrito por VIEIRA et al. (2010).

$\mathrm{O}$ teor relativo de água (TRA) das pétalas foi estimado ao final do período de armazenamento a seco e após 4,8 , $12,16,20$ e 24 horas do retorno para a água. As pétalas foram retiradas inteiras e agrupadas em três. Em seguida, foram pesadas para obtenção da massa fresca e imersas em espuma de poliuretano saturada com água. As pétalas permaneceram na espuma até a completa saturação, por 24 horas, quando, então, foi feita uma nova pesagem para obtenção da massa túrgida. Em seguida, as pétalas foram colocadas em estufa a $70^{\circ} \mathrm{C}$, por 72 horas, para obtenção da massa seca constante. A estimativa do TRA foi feita segundo a fórmula descrita por ÁLVARES et al. (2007).

O fim da vida de vaso das inflorescências foi determinado, em dias, quando as hastes florais apresentavam $50 \%$ das flores murchas e/ou caídas (FINGER et al., 2008).

Para verificar a influência do corte da base no restabelecimento da absorção de água pelas hastes florais, as inflorescências foram armazenadas a seco por 36 horas, à temperatura de $24 \pm 2^{\circ} \mathrm{C}$ e UR de $85 \pm 2 \%$, previamente testado como o tempo crítico para indução do déficit hídrico com base nos resultados da capacidade de reidratação das hastes florais. Transcorrido esse período, fez-se o corte da base das hastes florais no comprimento de 0,$5 ; 1,0 ; 2,0$; 3,0 e 4,0 cm em relação à extremidade basal. Em seguida, as hastes foram armazenadas em recipientes de vidros contendo $50 \mathrm{~mL}$ de água desionizada até o final da vida de vaso. Durante a avaliação da vida de vaso, a cada 48 
horas foram feitos o corte da base da haste nas mesmas alturas mencionadas anteriormente e a troca da água dos recipientes, com o objetivo de minimizar o desenvolvimento de microrganismos e o bloqueio vascular. As hastes foram analisadas quanto à vida de vaso a partir do início da reidratação e à taxa de absorção de água e de transpiração para determinação da razão absorção/transpiração. A taxa de absorção foi determinada conforme metodologia descrita por VAN DOORN et al. (2002). Para isso, as hastes foram dispostas em tubos individuais, inicialmente pesados, contendo $50 \mathrm{~g}$ de água desionizada. Diariamente, os tubos foram pesados com e sem as hastes. Para anular os efeitos da evaporação, a extremidade superior dos tubos foi envolvida com filme de PVC em quatro camadas. A taxa de absorção de cada solução foi obtida pelo volume de solução consumida em mg.dia ${ }^{-1}$, sendo calculada pela fórmula PAc $=(\mathrm{PAi}-\mathrm{PAf})$, em que PAc é a massa de água absorvida, PAf é o peso final de água após 24 horas e PAi é o peso inicial de água.

A determinação da taxa de transpiração das hastes foi determinada conforme metodologia descrita por VAN DOORN et al. (2002). As hastes foram dispostas em tubos individuais, inicialmente pesados, contendo $50 \mathrm{~g}$ de água desionizada. Diariamente, os tubos foram pesados com e sem as hastes. Para anular os efeitos da evaporação, a extremidade superior dos tubos foi envolvida com filme de PVC em quatro camadas. A taxa de transpiração foi estimada em $\mathrm{mg} \mathrm{dia}^{-1}$ pela fórmula $\mathrm{T}=(\mathrm{PAi}+\mathrm{PAc})$ - PAf, em que T é a taxa de transpiração, PAi é o peso inicial de água, PAc é a massa de água absorvida e PAf é o peso final de água após 24 horas.

O delineamento experimental empregado foi o inteiramente casualizado, com seis repetições por tratamento, constituídas por quatro hastes florais em cada repetição, totalizando 16 inflorescências. Para a determinação das taxas de transpiração e absorção, foram utilizadas dezesseis repetições constituídas cada uma delas por uma haste floral.

Os dados coletados foram submetidos à análise de variância ANOVA e as médias, comparadas entre si pelo teste SCOTT-KNOT a 5\% de probabilidade.

\section{RESULTADOS E DISCUSSÃO}

Houve acentuada redução da massa fresca das inflorescências com o período de armazenamento a seco, com perda proporcional para os períodos mais longos de déficit hídrico (Figura 1). Após o estresse hídrico das hastes florais, houve aumento da matéria fresca, indicando grande taxa de absorção de água nas quatro primeiras horas de hidratação, independentemente do tempo de armazenamento a seco (Figura 1). Após esse período, a massa fresca se manteve praticamente inalterada no período de até 24 horas de reidratação. Para o estresse de 12 horas, houve recuperação completa da massa fresca nas primeiras 4 horas de hidratação, de modo semelhante ao comportamento das hastes controle (Figura 1). Por outro lado, nas hastes com 24, 36 e 48 horas de armazenamento a seco, a reidratação foi incompleta com recuperação de 97,5, 95,0 e $90,0 \%$ da massa fresca inicial das inflorescências, respectivamente (Figura 1). Esta recuperação parcial da massa fresca evidencia que o estresse hídrico causou um dano irreversível às hastes. Resultado semelhante foi observado em crisântemo, em que o armazenamento a seco de hastes florais, por uma hora, a $20^{\circ} \mathrm{C}$, resultou na redução da massa fresca durante as 23 horas em que as hastes permaneceram em água, evidenciando a não recuperação da turgescência dessas flores (VAN MEETEREN et al., 2006). Comparando com as alterações de massa fresca de E. ibaguense, verifica-se que esta espécie se mostrou resistente à falta de água.

De modo semelhante ao comportamento da massa fresca, o armazenamento a seco reduziu o teor de água das pétalas, cuja queda foi proporcional ao tempo do estresse hídrico (Figura 2). Nas hastes controle, a imediata hidratação causou um aumento no teor de água das pétalas nas primeiras 4 horas, seguido de um período de estabilização, com leve queda a partir de 12 horas em água (Figura 2). Somente as hastes com 12 horas de estresse tiveram recuperação total do teor de água das pétalas, atingindo nível do controle após 24 horas em água. Nas hastes armazenadas a seco por 24, 36 e 48 horas, a reidratação das pétalas foi parcial, permanecendo abaixo de $90 \%$ de hidratação, inferior às flores controle, mesmo após 24 horas de reidratação (Figura 2). WEINBERGER et al. (1972) consideram recuperada aquela planta em que ocorre a restauração de no mínimo $90 \%$ do teor relativo de água inicial após ter sido desidratada até um limite subletal de estresse. A falha das hastes estressadas por 24, 36 e 48 horas em recuperar os níveis de hidratação inicial das pétalas mostra que o dano do estresse foi persistente, afetando o equilíbrio hídrico das hastes.

Independentemente do tempo de armazenamento a seco, houve redução da vida de vaso das inflorescências. Para as hastes controle, o número de dias para ocorrer $50 \%$ de flores murchas e/ou caídas foi 5,8 dias. As hastes que sofreram estresse hídrico por 12, 24 e 36 horas tiveram vida de vaso de 4,8, 4,3 e 1,2 dias, respectivamente (Figura 3). As hastes que ficaram sob estresse por 48 horas não recuperaram a turgidez quando colocadas em água, tendo sido descartadas após 24 horas de reidratação. $\mathrm{O}$ armazenamento a seco das hastes por 12 horas foi suficiente para reduzir a vida de vaso das inflorescências.

Em muitas espécies de flores colhidas, o corte da base da haste pode restabelecer o balanço hídrico e prolongar a vida de vaso (FINGER e BARBOSA, 2006). No presente trabalho, o corte da base das hastes com 1, 2, 3, e 4 cm, após 36 horas de armazenamento a seco, elevou a vida de vaso das flores quando comparado às inflorescências colocadas em água, sem prévio corte da base (Figura 4). Porém, quando o corte foi de apenas $0,5 \mathrm{~cm}$ de comprimento, não houve efeito sobre a vida de vaso das inflorescências (Figura 4). Provavelmente, o corte de $0,5 \mathrm{~cm}$ não tenha eliminado o ar aspirado para o interior dos vasos do xilema, não permitindo assim o restabelecimento do fluxo de água. De modo semelhante ao E. ibaguense, um corte de $5 \mathrm{~cm}$ na base em flores de bouvardia, após armazenamento a seco, por 24 horas, levou à recuperação rápida do turgor quando as hastes foram colocadas em água (VASLIER e VAN DOORN, 2003).

Independentemente da execução do corte da base das 
hastes armazenadas a seco por 36 horas, a absorção de água foi superior à transpiração nas primeiras 12 horas de reidratação, visto que a razão transpiração/absorção foi de 0,3 (Figura 5). Após esse período, houve intensa elevação dessa razão, e após 24 horas em água ela esteve acima de 1,0 , indicando ter a taxa de transpiração superado a de absorção de água em todos os tratamentos (Figura 5). A repetição dos cortes de 0,$5 ; 1,0 ; 2,0 ; 3,0$ e 4,0 cm da base das hastes após 48 de reidratação melhorou a taxa de absorção de água, reduzindo temporariamente a razão transpiração/ absorção de água (Figura 5). De acordo com SANKAT e MUJAFFAR (1994), em flores de antúrio, os sintomas de déficit hídrico apareceram após 20 dias armazenadas à temperatura ambiente, quando a razão entre transpiração e a absorção de água excedeu 1,5. Este fenômeno também foi observado no presente trabalho em que as flores se apresentaram murchas entre o período de 24 e 48 horas e após 96 horas em água (Figura 5).

As inflorescências de E. ibaguense apresentaram elevada sensibilidade à falta de água após a colheita, e a recuperação da hidratação requer tratamentos adicionais de corte da base da haste, possivelmente o uso de tratamentos que promovam o desbloqueio dos vasos do xilema e tratamentos antietileno para evitar a murcha e a queda das flores (FINGER et al., 2008).

\section{CONCLUSÃO}

1. As inflorescências de E. ibaguense são sensíveis ao estresse hídrico induzido pelo armazenamento a seco das hastes cortadas.

2. Há recuperação da massa fresca das hastes e do TRA das pétalas ao serem colocadas em vaso com água após o armazenamento a seco por 12 horas a $24^{\circ} \mathrm{C}$.

3. Independentemente da duração do armazenamento a seco, houve redução da vida de vaso das inflorescências.

4. Recortes da base da haste com no mínimo $1,0 \mathrm{~cm}$ após o armazenamento a seco aumentam temporariamente a capacidade de absorção de água.

\section{AGRADECIMENTOS}

Agradecimentos à Capes, pela concessão da bolsa de mestrado a Joice Simone dos Santos.

\section{REFERÊNCIAS}

ÁlVARES, V.S. FINGER, F.L.; SANTOS, R.C.A.; NEGREIROS, J.R.S.; CASALI, V.W.D. 2007. Effect of pré-cooling on the postharvest of parsley leaves. Journal of Food, Agriculture and Environment, v. 5, n. 2, p. 3134, 2007.

BLEEKSMA, H.C.; VAN DOORN, W.G. Embolism in rose stems as a result of vascular occlusion by bacteria. Postharvest Biology and Technology, v. 29, p.335-341, 2003. Disponível em: <linkinghub.elsevier.com/retrieve/ pii/S0925521403000498>. Acesso em: 5 out. 2010.
CAMPANHA, M.M.; FINGER, F.L.; CECON, P. R.; BARBOSA, J.G. Water relations of cut bird-of-paradise (Strelitzia reginae Ait.) inflorescences. Revista Brasileira de Horticultura Ornamental. Campinas, v.3, n.1, p.2731, 1997.

CARNEIRO, T.F.; FINGER, F.L.; SANTOS, V.R.; NEVES, L.L.; BARBOSA, J.G. Influência da sacarose e do corte da base da haste na longevidade de inflorescências de Zinnia elegans. Pesquisa Agropecuária Brasileira, v.37, p.1065-1070, 2002. Disponível em: < www.scielo.br/ pdf/pab/v37n8/11665.pdf>. Acesso em: 29 set. 2010.

DURKIN, D. J. Factors affecting hydration of cut flowers. Acta Horticulturae, v.113, p.109-117, 1980.

FARAGHER, J.; STALER, T.; JOYCE, D; WILLIAMSON, V. Postharvest handling of Australian flowers - from Australian native plants and related species: a practical workbook. Victoria: RIRDC, 215p. 2002.

FINGER, F.L.; BARBOSA, J.G. Postharvest physiology of cut flowers. In: NOUREDDINE, B., NORIO, S. (Eds.). Advances in Postharvest Technologies for Horticultural Crops. Kerala, India: Research Signpost, 2006. p. 373-393.

FINGER, F.L.; MORAES, P.J.; MAPELI, A.M.; BARBOSA, J.G.; CECON, P.R. Longevity of Epidendrum ibaguense flowers as affected by pre-loading treatments and vase solution. Journal of Horticultural Science and Biotechnology, v. 83, p.144-147, 2008.

LEONARD, R.T.; NELL, T.A.; SUZUKI, A.; BARRETT, J.E.; CLARK, D.G. Evaluation of long term transport of Colombian grown cut roses. Acta Horticulturae, v.543, p.293-297, 2001.

MENEGUCE, B; OLIVEIRA, R.B.D.; FARIA, R.T. Propagação vegetativa de Epidendrum ibaguense Lindl. (Orchidaceae) em substratos alternativos ao xaxim. Ciências Agrárias, Londrina, v. 25, n. 2, p. 101-106, abr/ junho, 2004.

MORAES, P.J.; FINGER, F.L.; BARBOSA, J.G.; CECON, P.R. Longevidade pós-colheita da orquidea Epidendrum ibaguense Kunth. Revista Brasileira de Horticultura Ornamental, Campinas, v.13, n.1, p.31-37, 2007.

MORAES, P.J.; FINGER, F.L.; MAPELI, A.M; , CECON, P.R.; BARBOSA, J.G. Growth and flower development of Epidendrum ibaguense orchid. Acta Horticulturae, v.813, p.565-569, 2009.

SANKAT, C.K.; MUJAFFAR, S. Water balance in cut anthurium flowers in storage and its effect on quality. Acta Horticulturae, v. 368, p.723-732, 1994.

SILVA, A.T. C.. Manejo pós-colheita de Alpinia purpurata Vieill. Universidade Federal de Alagoas-UFAL, Centro de Ciências Agrárias. Dissertação, Rio Largo, 2006, 108p. 
SUZUKI, A.; LEONARD, R.T.; NELL, T.A.; BARRETT, J.E.; CLARK, D.G. Effects of retail hydration on water uptake and quality of "Madame Delbard" roses after long term transport. Acta Horticulturae, v.543, p.251-256, 2001 .

VAN DOORN, W.G. Aspiration of air at the cut surface of rose stems and its effect on the uptake of water. Journal of Plant Physiology, v.137, p.160-164, 1990.

VAN DOORN, W.G. Water relations of cut flowers. Horticultural Reviews, v.18, p.1-85. 1997.

VAN DOORN, W.G.; ABADIE, P.; BELDE, P.J.M. Alkylethoxylate surfactants for rehydration of roses and Bouvardia flowers. Postharvest Biology and Technology, v.24, p. 327-333, 2002.

VAN MEETEREN, U.; VAN GELDER, A.; SLOOTWEG, C.; VAN IEPEREN, W. Should be reconsider the use of deionized water as control vase solutions? Acta Horticulturae, v.543, p. 257-264, 2001. Disponível em: <linkinghub.elsevier.com/retrieve/pii/ S0925521401001521>. Acesso em 29 set. 2010.
VAN MEETEREN, U.; ARÉVALO-GALARZA, L.; VAN DOORN, W.G. Inhibition of water uptake after dry storage of cut flowers: Role of aspired air and woundinduced processes in Chrysanthemum. Postharvest Biology and Technology, v.41, p.70-77, 2006. Disponível em: <linkinghub.elsevier.com/retrieve/pii/ S0925521406000846>. Acesso em 30 set. 2010.

VASLIER, N.; VAN DOORN, W.G.. Xylem occlusion in bouvardia flowers: evidence for a role of peroxidase and catechol oxidase. Postharvest Biology and Technology, v.28, p.231-237, 2003. Disponível em: <linkinghub. elsevier.com/retrieve/pii/S0925521402001977>. Acesso em 5 out. 2010 .

VIEIRA, L.M.; MENDES, T.D.C.; FINGER, F.L.; BARBOSA, J.G.. Soluções conservantes prolongam a vida de vaso de inflorescências cortadas de boca-de-leão. Ciência Rural, v.40, p. 827-832, 2010. Disponível em: $<$ www.scielo.br/pdf/cr/v40n4/a528cr2515.pdf $>$. Acesso em 5 out. 2010.

WEINBERGER, P.; ROMERO, M.; OLIVA, M. Contribution to the method for the determination of sublethal water deficit. Flora, v. 161, p, 555-561, 1972.

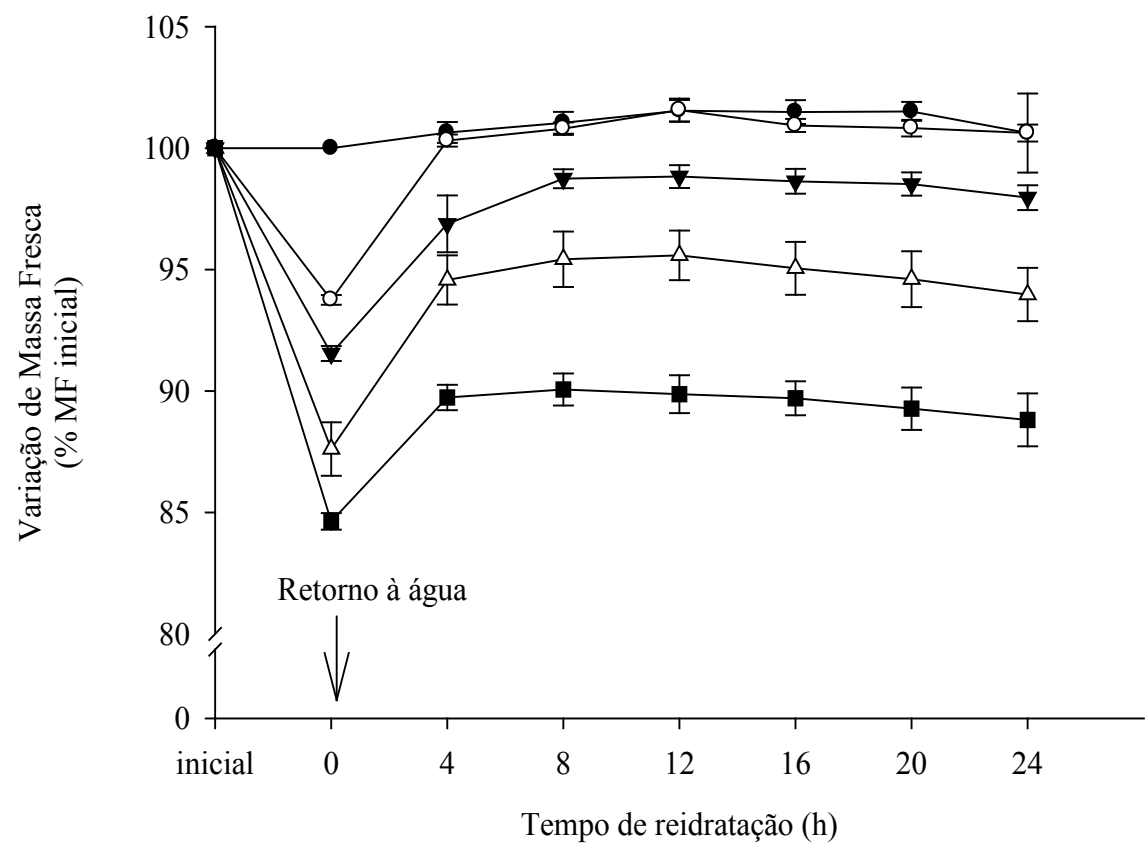

Figura 1. Variação percentual de massa fresca das inflorescências de Epidendrum ibaguense submetidas a 0 $(\bullet), 12(\circ), 24(\boldsymbol{\nabla}), 36(\Delta)$ e $48(\boldsymbol{\bullet})$ horas de armazenamento a seco, em função do tempo de reidratação. As barras verticais representam o erro padrão da média. Viçosa-MG, 2008.

Figure 1. Percentage changes of fresh weight of Epidendrum ibaguense flowers submitted to $0(\bullet), 12(0)$, $24(\mathbf{\nabla}), 36(\Delta)$ e $48(\mathbf{\square})$ hours of dry storage, according to the time of rehydration. Vertical bars represent the standard error of mean. Viçosa-MG, 2008. 


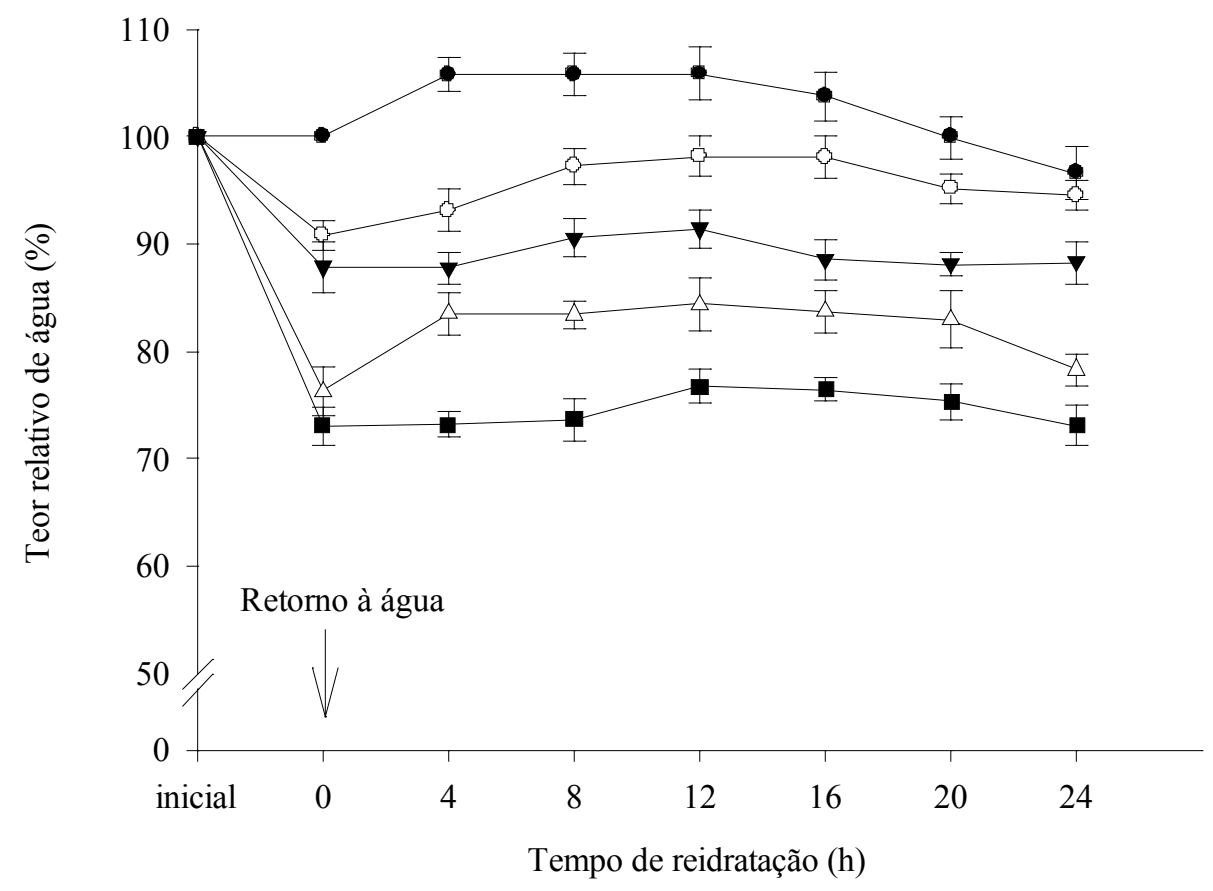

Figura 2. Teor relativo de água de flores de Epidendrum ibaguense submetidas a $0(\bullet), 12(\circ), 24(\boldsymbol{\nabla})$, $36(\Delta)$ e $48(\square)$ horas de armazenamento a seco, em função do tempo de reidratação. As barras verticais representam o erro padrão da média. Viçosa-MG, 2008.

Figure 2. Relative water content of Epidendrum ibaguense flowers submitted to $0(\bullet), 12(0), 24(\boldsymbol{\nabla})$, $36(\Delta)$ e 48 (a) hours of dry storage, according to the time of rehydration. Vertical bars represent the standard error of mean. Viçosa-MG, 2008.

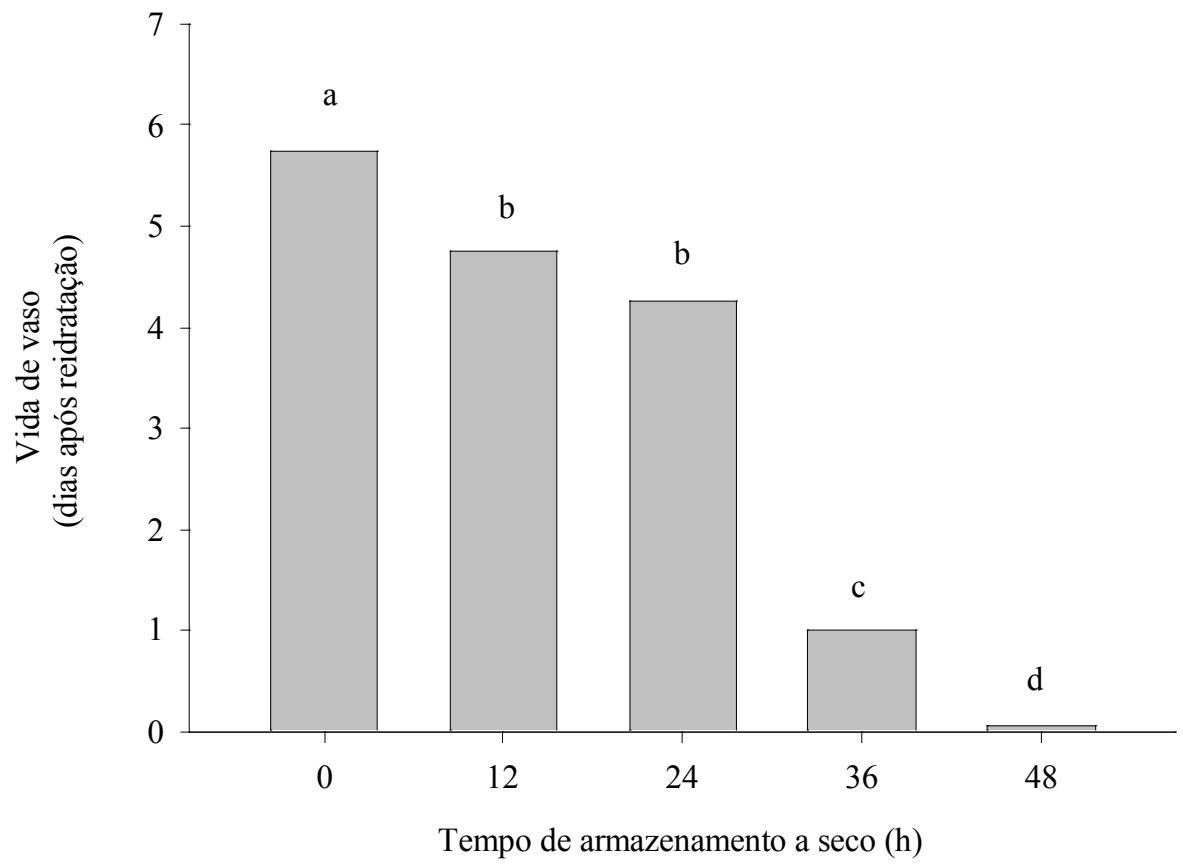

Figura 3. Vida de vaso de flores de Epidendrum ibaguense submetidas a 0, 12, 24, 36 e 48 horas de armazenamento a seco. Médias seguidas pela mesma letra não diferem entre si pelo teste de Scott-Knott ao nível de 5\% de probabilidade.Viçosa-MG, 2008.

Figure 3. Vase life of Epidendrum ibaguense flowers submitted to 0, 12, 24, 36 and 48 hours of dry storage. Means followed by same letter do not differ by Scott-Knott test at 5\% of probability. Viçosa-MG, 2008. 


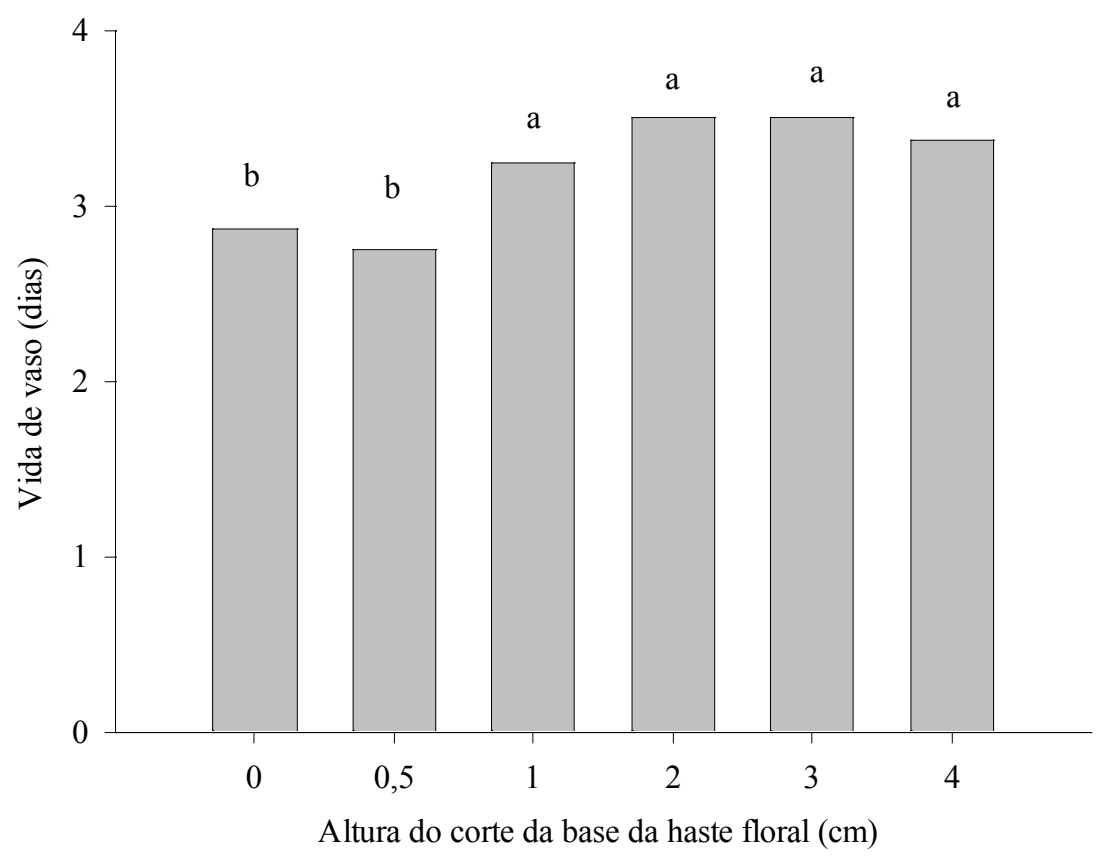

Figura 4. Vida de vaso de flores de Epidendrum ibaguense submetidas ao corte a 0, 0,5, 1,0, 2,0, 3,0, e 4,0 cm da base da haste após 36 horas de armazenamento a seco. Médias seguidas pela mesma letra não diferem entre si pelo teste de Scott-Knott ao nível de 5\% de probabilidade. Viçosa-MG, 2008.

Figure 4. Vase life of Epidendrum ibaguense flowers submitted to the re-cut at 0, 0,5, 1,0, 2,0, 3,0 and 4,0 cm from the base of the stem, after 36 hours of dry storage. Means followed by same letter do not differ by Scott-

Knott test at 5\% of probability. Viçosa-MG, 2008.

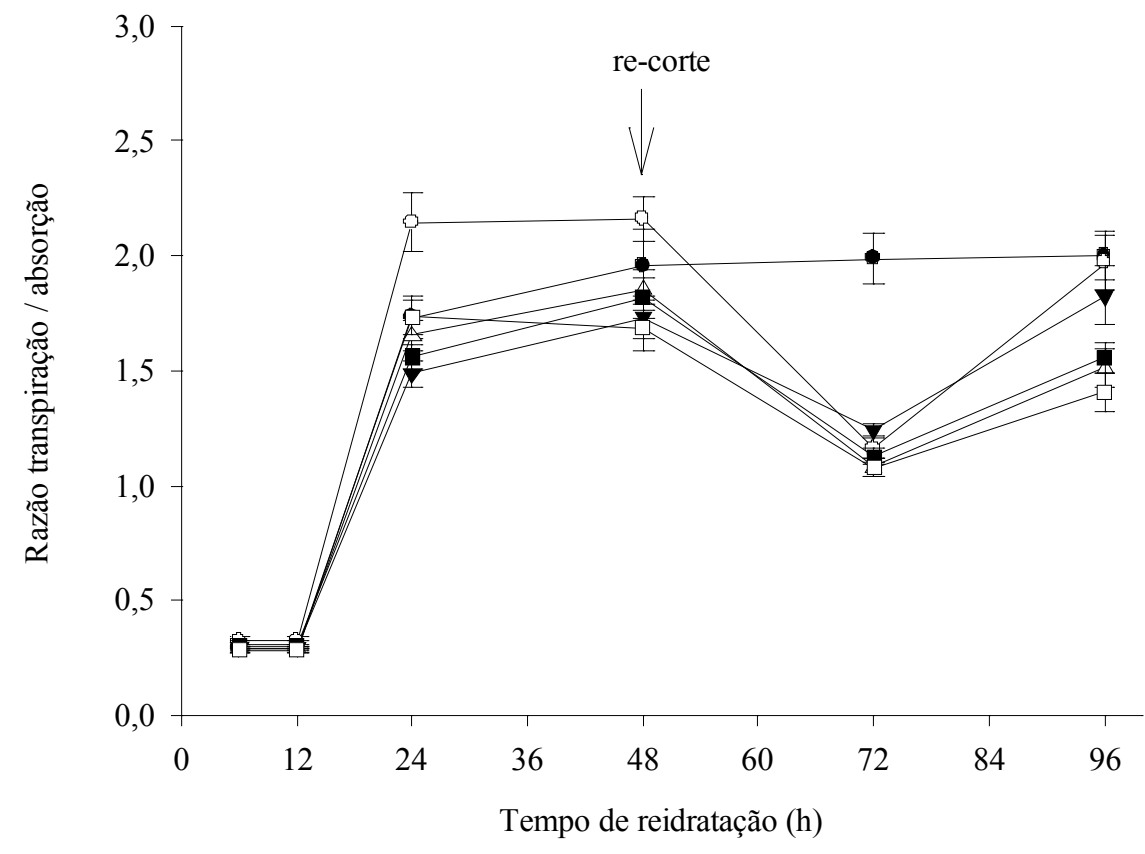

Figura 5. Razão transpiração/absorção em flores de Epidendrum ibaguense submetidas ao corte a 0 (sem corte) (•), 0,5 $(\circ), 1,0(\boldsymbol{\nabla}), 2,0(\Delta), 3,0(\mathbf{\square})$, e 4,0 (口) cm da base da haste após 36 horas de armazenamento a seco e ao recorte a 48 horas de reidratação. As barras verticais representam o erro padrão da média, Viçosa-MG, 2008.

Figure 5. Rate of transpiration/absorption of the flowers Epidendrum ibaguense submitted to the cut at 0 (no cut) ) (•), 0,5 (०), 1,0 ( $\mathbf{\nabla}), 2,0(\Delta), 3,0(\mathbf{\square}), e$ 4,0 (口) cm from the base of the stem after 36 hours of dry storage and re-cut to 48 hours of rehydration. Vertical bars represent the standard error of mean, Viçosa-MG, 2008. 